Extended Abstract

\title{
Self-Organisation of Symbolic Information
}

\author{
Rainer Feistel \\ Leibniz Institute for Baltic Sea Research (IOW), D-18119 Warnemünde, Germany
}

E-Mail: rainer.feistel@io-warnemuende.de

Accepted:

\section{Introduction}

The formulation of a unified theory of information still poses a fundamental scientific challenge $[1,2]$. Information may be present or being transmitted in two different ways, either in native form by physical structures or in symbolic form by coded sequences of letters, images, etc. The latter form is equivalent (i.e., necessary and sufficient) to the existence of life; there is no life without symbolic information processing, and there is no symbolic information without life [2]. In contrast, structural information may be attributed to any physical, unenlivened processes or structures and can usually be quantified in terms of entropy. The self-organised emergence of symbolic information out of structural information exhibits typical features of kinetic phase transitions of the $2^{\text {nd }}$ kind and is referred to as a "ritualisation" transition [3], a term coined by Huxley [4] in behavioural biology for the development of signal-activity out of use-activity [5]. The origin of life, the appearance of human language or the establishment of social categories such as private property or money can be understood as ritualisation transitions [2,3]. All these transitions have in common that as their results, arbitrary symbols are produced and recognised by information-processing devices, by "senders" and "receivers" in the sense of Shannon's information theory, which had developed during an evolutionary process along with the actual set of symbols and of coding rules (such as "grammars" [6,7]), and replaced a related original non-symbolic causal chain.

A written text such as this abstract is typically a physical structure consisting of dark and light dots. The information carried by the text is in no way reducible to the physical properties of the given spatial distribution of dye; in this sense symbolic information is an emergent property. However, written text appeared as a result of the evolution of human language from more primitive signal systems used by 
animals, and those in turn from elementary physical and chemical processes. Here, ritualisation is understood as a universal qualitative transition from elementary structural to emergent symbolic information properties in the course of evolution processes. Another emergent property that often accompanies symbolic information is its value, such as selective values in biology or exchange values in economy; this aspect will elucidated in more detail in the presentation of Werner Ebeling at this conference.

\section{Methods}

Derived from thermodynamics [8] and the mathematical theories of bifurcations and catastrophes, the concept of kinetic phase transitions in non-equilibrium systems [9] appeared to be a useful tool also for the physical description of evolution processes which are thought of as potentially unlimited series of dynamic instabilities and subsequent steps of self-organisation [2,6]. In combination with empirical paradigms developed in population biology [10], ethology [5], evolution theory of culture and religion $[11,12]$, language theory $[13,14]$ and economy [15], the striking qualitative similarity of the transition processes observed in those fields motivates their unified description from the perspective of selforganisation of information $[2,3,16]$.

\section{Results and Discussion}

The very first ritualisation transition was the origin of life when chemical interaction of randomly assembled organic molecules became controlled by a primitive precursory genetic code, executed by catalysts forming a simple translation apparatus enclosed in a proto-cellular compartment [2,17]. Ritualisation was and is an extremely successful transition phenomenon in evolution that has been repeated many times after it once had happened for the first time, as briefly summarised in Table 1.

Table 1. Estimated time table of significant ritualisation transitions in evolution history (modified from [2]). Starting with the genetic code, each qualitative step of symbolic information processing gave rise to novel emergent properties, valuation and competition mechanisms.

\begin{tabular}{|c|c|c|}
\hline Time BP & Evolution stage & Emergence of \\
\hline $4500 \mathrm{Myr}$ & Random catalysis & Physico-chemical networks \\
\hline $3700 \mathrm{Myr}$ & Genetic code & Biological systems \\
\hline $1200 \mathrm{Myr}$ & Sexual reproduction & Sexual selective values \\
\hline $635 \mathrm{Myr}$ & Morphogenesis & Multicellular organisms \\
\hline $518 \mathrm{Myr}$ & Neuronal networks & Individual information gathering \\
\hline $2 \mathrm{Myr}$ & Human spoken language & Human social systems \\
\hline $5500 \mathrm{yr}$ & Written numbers & Book-keeping of personal property \\
\hline $2600 \mathrm{yr}$ & Coined money & Market economy, exchange values \\
\hline $2600 \mathrm{yr}$ & Greek natural science & Scientific information accumulation \\
\hline
\end{tabular}

Phase transitions of the $2^{\text {nd }}$ kind own the characteristics [8] that the two phases involved (i) possess different symmetries, (ii) are indistinguishable at the transition threshold and (iii) cannot stably coexist 
in space. The new symmetry that emerges during the ritualization transition is coding invariance; if one set of given symbols, say, Latin letters, is replaced one-to-one by a completely different set of symbols, say, computer bits, the functioning of the entire system will remain unaffected if sender and received are modified accordingly. This is illustrated by the letter " $A$ " in Figure 1. In contrast, the picture on the left of Figure 1 cannot be arbitrarily modified without losing its meaning, the ox. The new, neutrally stable, so-called Goldstone mode related to the coding symmetry is found in every symbolic information system; it permits slow drift and diversification of the set of symbols and at the same time preserves a trace of its own evolution history. The paradox discussed already by Herder in 1772 [13] whether our spoken words are completely arbitrary creations of the human mind or are of traceable onomatopoetic origin may be explained this way.

Figure 1. Example for the ritualization transition in the evolution of the human written language. A physical object such as an ox is originally described by a symbolic picture (a

"caricature") which gradually develops into a mere symbol, losing any relation to the original object. The information represented by the final symbol(s) is an emergent property as its meaning cannot be derived from the physical dye distribution of letters such as "A".

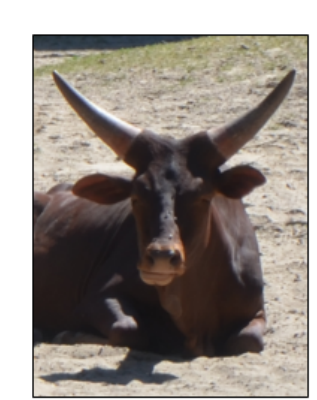

Reality / Picture
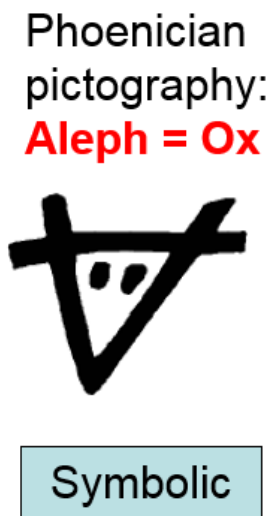

Picture
Phoenician phonetic language:

Aleph $=0 \mathbf{x}$

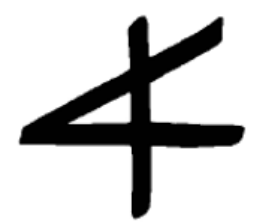

Symbol
Roman

Capitalis:

Alpha

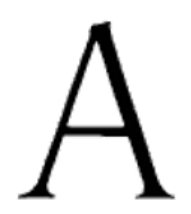

Evolution of

Symbolic

Languages

\section{Conclusions}

Symbolic information systems appeared exclusively during the evolution of life, if technical devices are counted as "honorary living things" [18]. Similarly exclusively, ritualisation may be the universal transition process by which symbolic information emerged from structural information. Accordingly, very different symbolic information system have universal properties in common which find their roots in the properties of the ritualisation transition, in particular, in the coding symmetry which fundamentally distinguishes symbolic from native information. In turn, the physical carriers of symbols possess native information; their physical structures are percussions of their own evolution history. The way how emergent symbolic information, the "soul", became liberated from its original physical nature, the "body", may be an evolutionary approach to a future unified theory of information.

\section{Acknowledgments}

The author is indebted to Wolfgang Hofkirchner for being invited to the ISIS Summit Vienna 2015. 


\section{References and Notes}

1. Hofkirchner, W., Ed. The Quest for a Unified Theory of Information; Gordon and Breach: Amsterdam, The Netherlands, 1999.

2. Feistel, R.; Ebeling, W. Physics of Self-Organization and Evolution; Wiley-VCH: Weinheim, Germany, 2011.

3. Feistel, R. Ritualisation und die Selbstorganisation der Information. In Selbstorganisation und Determination; Niedersen, U.; Pohlmann, L., Eds.; Duncker \& Humblot: Berlin, Germany, 1990; Volume 1, pp. 83-98.

4. Huxley, J. The ritualization of Behaviour in animals and man. Philosophical Transactions of the Royal Society 1966, 251, 249-269.

5. Tembrock, G. Grundlagen des Tierverhaltens; Akademie-Verlag: Berlin, Germany, 1977.

6. Ebeling, W.; Feistel, R. Physik der Selbstorganisation und Evolution; Akademie-Verlag: Berlin, Germany, 1982.

7. Jiménez-Montaño, M.A.; Feistel, R.; Diez-Martínez, O. On the information hidden in signals and macromolecules: I. Symbolic time-series analysis. Nonlinear Dynamics, Psychology, and Life Sciences 2004, 8, 445-478

8. Landau, L.D.; Lifshitz, E.M. Statistical Physics; Reed Educational and Professional Publishing: Oxford, UK, 1980.

9. Haken, H. Synergetics: An Introduction; Springer-Verlag: Berlin, Germany, 1978.

10. Fisher, R.A. The Genetical Theory of Natural Selection; Clarendon Press; Oxford, UK, 1930.

11. Koenig, O. Kultur und Verhaltensforschung; DTV, München, 1970.

12. Wunn, I.; Urban, P.; Klein, C. Götter - Gene - Genesis: Die Biologie der Religionsentstehung; Springer Spektrum; Berlin, Heidelberg, 2015.

13. Fitch, W.T. The evolution of language; Cambridge University Press: Cambridge, UK, 2010.

14. Ifrah, G. Universalgeschichte der Zahlen; Campus-Verlag: Fankfurt/Main, Germany, 1991.

15. Marx, K. Das Kapital, Erster Band; Dietz-Verlag: Berlin, Germany, 1951.

16. Ebeling, W.; Feistel, R. Selforganization of Symbols and Information. In Chaos, Information Processing and Paradoxical Games: The Legacy of John S Nicolis; Nicolis, G.; Basios, V., Eds.; World Scientific Pub Co.: Singapore, 2015; pp. 141-184.

17. Eigen, M. From Strange Simplicity to Complex Familiarity; Oxford University Press: Oxford, UK, 2013.

18. Dawkins, R. The Blind Watchmaker; W.W. Norton \& Co.: New York, 1996.

(C) 2015 by the authors; licensee MDPI and ISIS. This abstract is distributed under the terms and conditions of the Creative Commons Attribution license. 